\title{
Neuroleptic Malignant Syndrome (NMS) after Treatment with Metoclopramide - A Rare Case Report
}

\author{
Sourya Acharya ${ }^{1}$, Samarth Shukla², Amol Andhale², Akhilesh Annadatha ${ }^{4}$, Yash Gupte ${ }^{5}$ \\ 1,3,4,5 Department of Medicine, Datta Meghe Institute of Medical Sciences (Deemed to Be University), \\ Sawangi Meghe, Wardha, Maharashtra, India. ${ }^{2}$ Department of Pathology, Datta Meghe Institute of \\ Medical Sciences (Deemed to Be University), Sawangi Meghe, Wardha, Maharashtra, India.
}

\section{INTRODUCTION}

Neuroleptic Malignant Syndrome (NMS) is a medical emergency. It presents with mental status change, rigidity, fever, and autonomic dysfunction. It is caused by antipsychotics especially neuroleptic agents and certain antiemetic drugs like metoclopramide that block central dopamine pathways. We present a case of a 32year-old male chronic alcoholic who presented to us with alcohol withdrawal symptoms and was given injection metoclopramide and developed neuroleptic malignant syndrome (NMS).

Incidence rates for NMS range from 0.02 to 3 percent in patients treated with antipsychotic agents. ${ }^{1,2}$ Though it is commonly encountered in young adults, any age group can be affected. ${ }^{3,4}$ Males are two-fold more affected than females. ${ }^{4}$

Metoclopramide, a commonly used anti-emetic agent has anti-dopaminergic properties and can give rise to development of NMS. The signs and symptoms of NMS include hyperthermia, altered mental status, muscular rigidity resembling extrapyramidal rigidity, autonomic instability, diaphoresis, hyper salivation, dysphagia, tachycardia, hypertension. NMS if left untreated, is usually fatal. So, early recognition and treatment is of great importance.

\section{PRESENTATION OF CASE}

A 25-year-old male, labourer by occupation was admitted with complaints of fever, confusion, decrease in activity with stiffness of whole body and difficulty in deglutition since 4 days. On asking leading questions, the relative revealed that one week prior to onset of these features, he was admitted to a private nursing home for food poisoning and was treated with intravenous antibiotics and metoclopramide 10 mg 6 doses over 2 days and was discharged. He developed the above symptoms the next day after discharge. His past medical history was unremarkable. He was nonalcoholic. There was no history of hypertension and diabetes mellitus.
Corresponding Author: Dr. Sourya Acharya, Professor, Department of Medicine, Datta Meghe Institute of Medical Sciences (Deemed to Be University), Sawangi Meghe, Wardha, Maharashtra, India.

E-mail: souryaacharya74@gmail.com

DOI: $10.14260 / \mathrm{jemds} / 2020 / 671$

How to Cite This Article:

Acharya S, Shukla S, Andhale A, et al. Neuroleptic malignant syndrome (NMS) after treatment with metoclopramide- a rare case report. J Evolution Med Dent Sci 2020;9(41):3065-3066, DOI: $10.14260 / \mathrm{jemds} / 2020 / 671$

Submission 16-05-2020,

Peer Review 02-92020,

Acceptance 09-09-2020,

Published 12-10-2020.

Copyright (C) 2020 Sourya Acharya et al. This is an open access article distributed under Creative Commons Attribution License [Attribution 4.0 International (CC BY 4.0)] 
On examination, pulse was $110 / \mathrm{min}$, regular, blood pressure was 148 / $88 \mathrm{mmHg}$. Other systemic examination was normal. On neurological examination, he was found to be confused. GCS: was 13 (E - 4, V - 4, M - 5). His speech was hypophonic and slurred. Face was mask like. Hyper salivation was present. Cranial nerve examination revealed normal pupillary reflex, no ophthalmoplegia and normal gag reflex. Motor system examination showed generalised lead-pipe type of rigidity in all four limbs. Power overall was grade 4 . Tremors were present in lower extremities and cogwheeling was present in wrist joint. Deep tendon reflexes were brisk. Bilateral plantars showed withdrawal responses. Gait revealed flexion posture, no arm swing and turning en bloc because of rigidity.

Investigations: $\mathrm{Hb}$ - 10 gram \%, TLC - $5600 / \mathrm{mm}^{3}$, Malaria antigen test, IgM Dengue, blood and urine culture was normal. CXR was normal. Urine was positive for myoglobin. Blood urea - $78 \mathrm{mg} / \mathrm{dL}$, serum creatinine - $3.8 \mathrm{mg} / \mathrm{dL}$, serum LDH - 188 U / L (normal - 140 - 280), serum total CPK - $1028 \mathrm{U} / \mathrm{L}$ (normal; 40 - 308), serum sodium was normal, potassium was $5.8 \mathrm{mg} / \mathrm{dL}$. LFT was normal. CT brain was normal. After ruling out other possible infections and taking into consideration the extra pyramidal symptoms along with high CPK levels, and causality of patient condition with the metoclopramide administration, a clinical diagnosis of the neuroleptic malignant syndrome was made.

The patient was treated with IV fluids, IV calcium gluconate, glucose insulin drip, carbidopa $25 \mathrm{mg} /$ levodopa $100 \mathrm{mg}$ PO BID, baclofen $5 \mathrm{mg}$ PO BID for rigidity. He became afebrile after 12 hours. Repeat CPK levels after 24 hours was $580 \mathrm{U} / \mathrm{L}$ and physical examination showed improvement in rigidity. Renal profile became normal by $4^{\text {th }}$ day, repeat urine examination did not show myoglobinuria. Patient was discharged on the $5^{\text {th }}$ day.

\section{DISCUSSION}

NMS was first described by Delay et al in $1968 .{ }^{5}$ The classical features of NMS are fever, muscle rigidity, tachycardia, diaphoresis, hypertension and altered mental status. ${ }^{6}$ Dopamine receptor blockade gives rise to NMS.7,8

The incident development of NMS after exposure to neuroleptic agents is approximately $0.5 \%$ to $1.4 \%$. It can also occur as a side effect of non-neuroleptic agents like metoclopramide, that blocks the central dopaminergic pathways in brain. 9,10

The common side effects of metoclopramide are akathisia, dystonia, oculogyric crisis but rarely it can cause serious effects like NMS. Dystonic reactions usually involve locally in face, neck or back, but it does not affect mentation like NMS. ${ }^{11}$

Metoclopramide induced dystonia usually involves the face, neck and back muscles sparing the higher functions of brain. Myoglobinuric renal failure secondary to rhabdomyolysis can occur like in our case. We presume that food poisoning induced vomiting and dehydration and administration of metoclopramide lead to NMS in our patient. The treatment of NMS includes stopping the offending agent, correction of dehydration and electrolyte imbalance, treating sepsis (if present) with antibiotics, DVT prophylaxis. The drugs used to treat NMS are IV dantrolene, benzodiazepines, dopamine agonists like bromocriptine, levodopa / carbidopa, amantadine, baclofen etc. ${ }^{11}$ Few evidence based studies suggest that ECT is a reasonable treatment modality. ${ }^{12,13}$ Most episodes resolve within two weeks. ${ }^{3}$ Mortality rates vary between 5 to 20 percent. 1,3

\section{CONCLUSIONS}

NMS is a rare fatal complication of metoclopramide therapy. Treatment usually is supportive in the form of stopping of the offending drug, correction of hydration, and electrolyte imbalance. Specific treatment is with drugs like dantrolene, dopamine agonists, and benzodiazepines.

Financial or Other Competing Interests: None.

\section{REFERENCES}

[1] Levenson JL. Neuroleptic malignant syndrome. Am J Psychiatry 1985;142(10):1137-45.

[2] Velamoor VR. Neuroleptic malignant syndrome. Recognition, prevention and management. Drug Saf 1998;19(1):73-82.

[3] Caroff SN, Mann SC. Neuroleptic malignant syndrome. Med Clin North Am 1993;77(1):185-202.

[4] Keck PE, Pope HG, Cohen BM, et al. Risk factors for neuroleptic malignant syndrome. A case-control study. Arch Gen Psychiatry 1989;46(10):914-8.

[5] Delay J, Deniker P. Drug-induced extrapyramidal syndromes. In: Vinken PJ, Bruyn GW, eds. Handbook of clinical neurology: diseases of the Basal Ganglia. Vol. 6. New York: Elsevier North Holland 1968:248-66.

[6] Silva RR, Munoz DM, Alpert M, et al. Neuroleptic malignant syndrome in children and adolescents. J Am Acad Child Adolesc Psychiatry 1999;38(2):187-94.

[7] Adnet P, Lestavel P, Krivosic-Horber R. Neuroleptic malignant syndrome. Br J Anaesth 2000;85(1):129-35.

[8] Henderson VW, Wooten GF. Neuroleptic malignant syndrome: a pathogenetic role for dopamine receptor blockade? Neurology 1981;31(2):132-7.

[9] Knight ME, Roberts RJ. Phenothiazine and butyrophenone intoxication in children. Pediatr Clin North Am 1986;33(2):299-309.

[10] Strawn JR, Keck PE, Caroff SN. Neuroleptic malignant syndrome. Am J Psychiatry 2007;164(6):870-6.

[11] Henderson A, Longdon P. Fulminant metoclopramide induced neuroleptic malignant syndrome rapidly responsive to intravenous dantrolene. Aust $\mathrm{N} \mathrm{Z} \mathrm{J} \mathrm{Med}$ 1991;21(5):742-3.

[12] Trollor JN, Sachdev PS. Electroconvulsive treatment of neuroleptic malignant syndrome: a review and report of cases. Aust N Z J Psychiatry 1999;33(5):650-9.

[13] Morcos N, Rosinski A, Maixner DF. Electroconvulsive therapy for neuroleptic malignant syndrome: a case series. J ECT 2019;35(4):225-30. 